11

\title{
Радиопоглощающие свойства полимерных композитов на основе шунгита и углеродного наноматериала „Таунит-М“
}

\author{
(C) Е.И. Теруков, ${ }^{1,2}$ А.А. Бабаев, ${ }^{3}$ А.Г. Ткачев, ${ }^{4}$ Д.В. Жилина ${ }^{3}$ \\ ${ }^{1}$ Физико-технический институт им. А.Ф. Иофффе РАН, \\ 194021 Санкт-Петербург, Россия \\ ${ }^{2}$ ООО „НТЦ тонкопленочных технологий в энергетике“, \\ 194064 Санкт-Петербург, Россия \\ ${ }^{3}$ Институт физики им. Х.И. Амирханова Дагестанского НЦ РАН, \\ 367003 Махачкала, Россия \\ ${ }^{4}$ Тамбовский государственный технический университет, \\ 392000 Тамбов, Россия \\ e-mail: eug.terukov@mail.ioffe.ru
}

(Поступило в Редакцию 20 сентября 2017 г.)

\begin{abstract}
Нанокомпозитные лакокрасочные материалы на основе углеродных наноматериалов и органических полимеров могут быть использованы для создания СВЧ защитных покрытий. Такие покрытия, обладают термо-, хемо-, плазмо- и радиационностойкими свойствами. Во многом эти свойства определяются концентрацией углеродных наноматериалов в композитах. При этом различные наноматериалы в составе таких покрытий показывают принципиально разные концентрационные зависимости электропроводности.
\end{abstract}

DOI: $10.21883 /$ JTF.2018.07.46181.2486

\section{Введение}

Хорошо известно, что макроскопический графит характеризуется высоким коэффициентом поглощения микроволнового излучения в широком диапазоне частот. Естественно ожидать наличия этого качества и в углеродных наноматериалах (УНМ). Введение УНМ в полимерную пленкообразующую матрицу в принципе может дать высокотехнологичный композиционный СВЧ поглощающий материал, устойчивый к разнообразным внешним условиям. Такие нанокомпозиты могли бы найти применение в качестве защитного материала как для персонала, так и для экранировки радиоэлектронной аппаратуры от внешнего электромагнитного СВЧ излучения.

Основополагающей работой в области поглощения электромагнитного излучения УНМ-содержащими материалами является серия отчетов одной из групп научно-исследовательского центра канадского военного министерства под руководством Дэррена Макейфа, в которых кроме исчерпывающих экспериментальных подробностей приводятся и важнейшие теоретические обоснования. Так, в отчете [1] приведены экспериментальные значения действительной и мнимой составляющих диэлектрической проницаемости композитов углеродных нановолокон (УНВ) и нанотрубок (УНТ) в полиметилметакрилате и полианилине, определены как частотные зависимости в диапазоне от 8 до $12 \mathrm{GHz}$, так и концентрационные. Кроме того, проведено сопоставление эффективности поглощения излучения УНВ и УНТ содержащими материалами. Для большинства нанокомпозитов диэлектрическая проницаемость составляет не менее $10+5 i$, достигая максимума в $70+20 i$ для одностенных УНТ и $20+25 i$ для УНВ. Тангенс угла потерь меняется мало и лежит в области 1.2-1.6. Таким образом, полимерные композиты с УНВ и УНТ наполнителями действительно могут быть использованы в качестве радиопоглощающих материалов (РПМ) для эффективного ослабления радиочастотных и СВЧ излучений.

В большинстве исследований мало внимания уделяется отражению СВЧ сигнала от композитов в дальнем поле, хотя последнее имеет большое значение как для фундаментальных, так и для прикладных исследований. Более того, можно предположить, что потенциальная применимость таких композитных материалов для решения практических, в том числе специальных, задач по созданию РПМ вынуждает проводить многие исследования в условиях секретности, и потому большой объем литературы оказывается недоступен. В нашей стране подобные исследования, насколько нам известно, только начинают развиваться $[2,3]$.

\section{1. Материал и методы исследования}

В качестве базовых материалов, относительно которых проводились основные измерения, использовали УНМ ООО „ТИТЦМ“ (г. Тамбов) марки „Таунит-М“ (ТУ 2166-001-02069286-2006) и шунгит (месторождение Карелия).

\section{1. Методика изготовления образцов РПМ}

С целью получения функциональных композиционных РПМ, учитывая необходимость нанесения защитных покрытий на поверхность облучаемых объектов, представ- 
Таблица 1. Сравнение морфологии и механических свойств композитных пленок

\begin{tabular}{|c|c|c|}
\hline & УНМ „Таунит-М““ & Шунгит \\
\hline Бутадиен-стирольный латекс & $\begin{array}{l}\text { Высокие прочность и пластичность } \\
\text { (выше, чем для чистого латекса); агрегация УНМ } \\
\text { с образованием } 2 D \text {-доменной структуры при } \\
\text { высоких концентрациях, высота рельефа } \\
\text { менее средней толщины слоя }\end{array}$ & \multirow{2}{*}{$\begin{array}{l}\text { Высокая гладкость рельефа } \\
\text { (высота менее } 0.1 \text { средней толщины } \\
\text { слоя), высокая гомогенность, } \\
\text { наличие критической концентрации, } \\
\text { ниже которой высоки прочность } \\
\text { и гибкость, выше - резкое снижение } \\
\text { когезии и адгезии, разрушение слоев } \\
\text { при высыхании }\end{array}$} \\
\hline Стирол-акрилатный латекс & $\begin{array}{l}\text { Такой же тип агрегации УНМ, хорошие } \\
\text { прочность и пластичность, высокая вязкость }\end{array}$ & \\
\hline
\end{tabular}

Таблица 2. Сравнение электрофизических свойств композитных пленок

\begin{tabular}{|c|c|c|}
\hline & УНМ „Таунит-М“ & Шунгит \\
\hline Бутадиен-стирольный латекс & $\begin{array}{l}\text { Немонотонная концентрационная зависимость } \\
\text { проводимости, сложное поведение вольт-амперной } \\
\text { характеристики, максимум проводимости } \\
\text { выше } 80 \mathrm{mS} / \mathrm{cm}\end{array}$ & \multirow{2}{*}{$\begin{array}{l}\text { Заметные значения проводимости } \\
\text { достигаются лишь при концентрациях } \\
\text { шунгита, превышающих критическую для } \\
\text { сохранения прочностных свойств композита. } \\
\text { Концентрационная зависимость проводи- } \\
\text { мости однородна, вольт-амперная характе- } \\
\text { ристика близка к омической }\end{array}$} \\
\hline Стирол-акрилатный латекс & То же, максимум проводимости не менее $10 \mathrm{mS} / \mathrm{cm}$ & \\
\hline
\end{tabular}

ляется целесообразным формирование защитных слоев лакокрасочными методами. В связи с этим для создания жидкофазных РПМ-композиций использовалась технология получения лакокрасочных материалов (ЛКМ), при которой УНМ выступают в роли „минеральных“ или окрашивающих наполнителей. Кроме того, за основу были взяты обычные рецептуры для получения антикоррозионных красок с частичной или полной заменой инертных наполнителей (мел, тальк) углеродными частицами. Антикоррозийный характер создаваемых композитов обусловлен необходимостью не только маскировки металлических поверхностей от электромагнитных излучений, но также их защиты от коррозийных процессов.

Шунгит и немодифицированный УНМ „Таунит-М“ легко входят в лаковые композиции различных пленкообразователей. Это было показано для лаков на основе бутадиен-стирольного и стирол-акрилатного латексов, а также для алкидного и эпоксидного лаков на органических растворителях. УНМ „Таунит-М“ легко входит в лаковые композиции даже в отсутствие поверхностноактивных веществ (ПАВ). Добавление ПАВ (лучше неионногенных) позволяет получать композиции с приемлемой технологической вязкостью с содержанием УНМ до 40-45\%. Качество получаемых лаковых покрытий по своим прочностным характеристикам проходит через максимум при указанном содержании УНМ. Ниже критической концентрации УНМ покрытия гомогенны и прочны, обладают хорошей адгезией к стеклу и металлу; выше критической концентрации - резкое снижение когезии и адгезии к подложке, снижение прочности покрытий и их сплошности из-за растрескивания при высыхании.
Для выбора оптимальных соотношений УНМ и полимерных матриц и для проведения сопоставительных сравнений были приготовлены разнообразные сочетания УНМ „Таунит-М“ и шунгита с поли(бутадиенстирольным) латексом и алкидными смолами, а также поли(о-гидроксиамидами), переходящими при термообработке в термо-, хемо-, плазмо- и радиационностойкие полибензоксазолы. Для каждой комбинации наносились и высушивались слои, затем оценивались их свойства по разным параметрам. Ниже приведены сводные таблицы свойств созданных композитов, отдельно рассмотрены их механические характеристики и электрофизические параметры (табл. 1 и 2).

\section{2. Методика исследования СВЧ свойств}

Исследование СВЧ поглощения и отражения от поверхности композитных слоев производилось на специализированной установке. Рабочая частота генератора варьировалась в диапазоне $38-43 \mathrm{GHz}$, излучатель имел щелевую конфигурацию, образец устанавливался в дальней зоне электромагнитной волны на подвижной консоли с электроприводом. Фиксация амплитуды прошедшей и отраженной волн осуществлялась с помощью двух рупорных антенн. Щелевой излучатель встроен в резонатор сложной конструкции, позволяющий обеспечить оптимальные условия формирования волны. Использовалась модуляция СВЧ сигнала прямоугольными импульсами с частотой следования $2-5 \mathrm{kHz}$ и соответственно были применены частотно-селективные вольтметры Unipan, снабженные входами для синхросигнала, что обеспечивало повышенную стабильность их фазовых детекторов. 


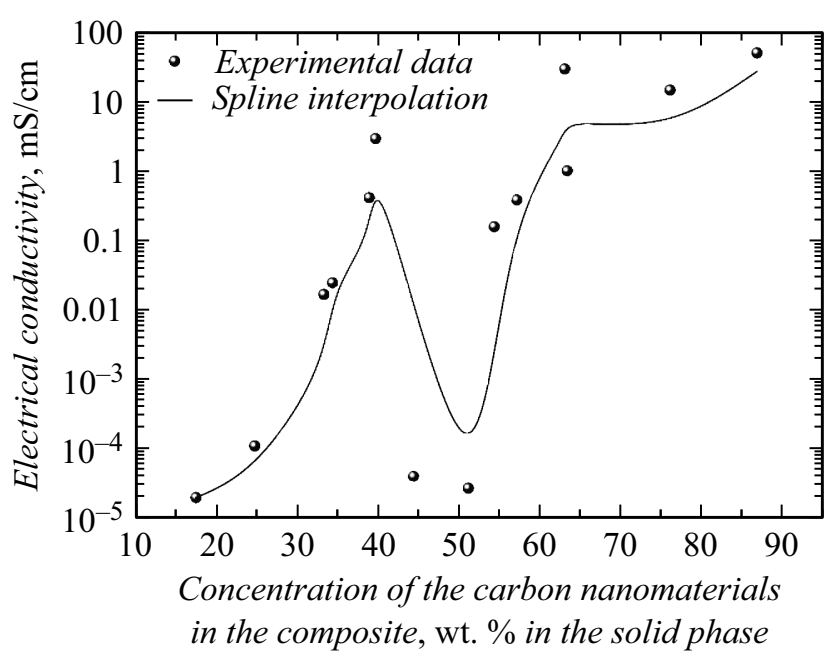

Рис. 1. Концентрационная зависимость электропроводности композита УНМ „Таунит-М“ в бутадиен-стирольном латексе.

Пространственное перемещение образца относительно статично закрепленных излучателя и приемных антенн позволяет сканировать поверхность и при надлежащей аналитической обработке получать сведения об однородности пространственного распределения значений СВЧ поглощения и отражения по площади образца. Также эта методика позволяет давать и более точную оценку интегральных параметров, усредненных по всему образцу. Наличие автоматизированного привода, а также автоматизированного снятия показаний приборов и записи их в файл персонального компьютера, сопряженного с измерительной установкой, исключает необходимость присутствия оператора непосредственно при измерении, что существенно улучшает помехозащищенность системы, заметно уменьшает уровень шумов. Для цифровой фиксации измеряемых сигналов использовался АЦП производства National Instruments, управляемый программной моделью, созданной и работающей в среде LabView. Описанная методика базируется на подходе, сформулированном и примененном в исследованиях $[4,5]$, где также показана и степень эффективности такого способа измерений в миллиметровом диапазоне.

\section{2. Результаты исследования и их обсуждение}

\section{1. Электрофизические свойства композитов с УНМ „Таунит-М“"}

На рис. 1 приведен график концентрационной зависимости проводимости образцов, измеренной на малом постоянном токе. Концентрации здесь заданы в массовых процентах по твердой фазе, что упрощает сравнение полученных результатов с некоторыми теоретическими положениями.

Особо отметим, что явно выбивающиеся из общей тенденции точки, соответствующие пониженной прово- димости в области концентраций $43-52 \%$, проверены неоднократно и на различных образцах, равно как и прочие точки, подозрительные на то, что они являются артефактами.

Минимум этой зависимости соответствует концентрации, при которой происходит резкое изменение морфологии слоев, шероховатости рельефа, СВЧ характеристик. Примечательно, что если показатели рельефа меняются на десятки процентов, то проводимость меняется на несколько порядков. Это позволяет допустить экспоненциальную зависимость проводимости от пространственных характеристик проводящей структуры, по крайней мере вблизи критической концентрации. Подобная зависимость, насколько известно, имеет место в модели прыжковой проводимости. Однако более последовательное объяснение обнаруженной зависимости можно дать, исходя из представлений теории перколяции. Согласно этой теории, вблизи порога протекания проводимость изменяется следующим образом:

$$
\begin{array}{lll}
\sigma=\sigma_{0}\left(x-x_{c}\right)^{t} & \text { при } & x \geq x_{c}, \\
\sigma=0 & \text { при } & x<x_{c},
\end{array}
$$

где $\sigma_{0}-$ проводимость при $100 \%$ концентрации проводящей фазы (в нашем случае это УНМ „Таунит-

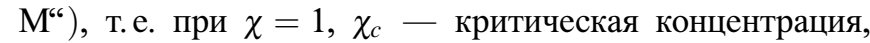
соответствующая порогу протекания, $t-$ критический индекс проводимости.

Известно, что для двумерной системы $\chi_{c}=0.5$, для трехмерной $\chi_{c}=0.16[6,7]$. Если перестроить рис. 1 в линейных координатах, то те точки, в которых должны начинаться ветви степенной зависимости, аппроксимирующие соответствующие участки экспериментальной кривой, будут отвечать значениям концентрации 15-20 и $45-50 \%$ (что, впрочем, видно и в координатных осях pис. 1), или значениям $\chi_{c}=0.15-0.20$ и $0.45-0.50$. Таким образом, для второй ветви на рис. 1 критическая концентрация уверенно соответствует двумерной системе, для первой же близка к системе с размерностью 3 либо немного ниже.

Если наше предположение о равномерном распределении частиц УНМ в объеме образца при малых концентрациях и их кластеризации в крупные агломераты при достижении критической концентрации перевести на язык терминов теории перколяции, то следует говорить о трехмерной системе, переходящей в упорядоченную сеть агломератов во всех трех измерениях, в некоторый момент сопоставимых по размеру с толщиной слоя, следовательно, ограниченных по локализации в одном направлении, а значит, двумерно организованных.

Тем самым минимум проводимости при концентрации около $50 \%$ в твердой фазе может быть объяснен переходом от трехмерной к двумерной организации системы, т.е. переходом к той стадии роста кластеров УНМ в слое, при котором их средний размер достигает по порядку величины толщины слоя. 


\section{2. СВЧ свойства композитов}

Интерес к СВЧ свойствам УНМ-содержащих материалов вполне закономерен в первую очередь по причине высокого СВЧ поглощения в макроскопическом графите. Для оценки свойств композитов на основе УНМ „Таунит-М“ мы сравнили их с аналогичными композитами на основе шунгита - минерала, применяемого в СВЧ экранах и состоящего не менее чем на $30 \%$ из углерода, не имеющего наноструктуры (оксиды алюминия, кремния и прочие соединения, обычные для подобных минеральных пород, также вносят свой вклад в поглощение микроволнового излучения).

Описанная в разделе 1.2 методика была использована для измерения параметров поглощения и отражения СВЧ излучения тремя сериями пленочных образцов: УНМ и шунгит в бутадиен-стирольном латексе и УНМ в поли(о-гидроксиамиде). Необходимо отметить, что в последнем случае для концентраций УНМ ниже $50-55 \%$ по массе в твердой фазе образующиеся образцы имели не вполне плоскопараллельную форму, вызывая сильную дифракцию на своих краях. В результате СВЧ волна фокусировалась в пространстве за образцом, формируя область не поглощения, а локального усиления сигнала, что препятствовало точному определению СВЧ параметров слоя. По этой причине ниже приводятся данные только для двух концентраций УНМ в поли(о-гидроксиамиде), для которых измеренные значения экспериментально достоверны. Кроме того, прогретый до температуры $350^{\circ} \mathrm{C}$ (термозадубленный) поли(огидроксиамид), превращающийся вследствие циклодегидратации в полибензоксазол, обладал существенно большим показателем поглощения, оценка которого в имеющихся экспериментальных условиях оказалась невозможной ввиду малости проходящего через образец сигнала.

На рис. 2 приведены данные по поглощению СВЧизлучения образцами УНМ „Таунит-М“ и шунгита в бутадиен-стирольном латексе, на рис. 3 - значения коэффициента отражения СВЧ излучения от соответствующих композитов. Отметим, что шкала концентраций пересчитана в массовые проценты по твердой фазе.

Приведенные на рис. 2 и 3 кривые, соответствующие композиту УНМ в поли(бутадиен-стироле), имеют не сильно выраженные, но все же заметные точки перегиба как по поглощению, так и по отражению при концентрации, близкой к критической. Для композита на основе шунгита этот эффект не наблюдается. Это показывает, что морфологические особенности композитных пленок влияют на их СВЧ параметры, несмотря на то, что пространственный параметр неоднородности рельефа всех образцов составляет менее 5\% от длины волны СВЧ излучения. По-видимому, надмолекулярная организация защитных покрытий влияет на СВЧ характеристики не прямо, а опосредованно, например, модулируя высокочастотную проводимость, которая, в свою очередь, отражается на показателях поглощения и отражения.

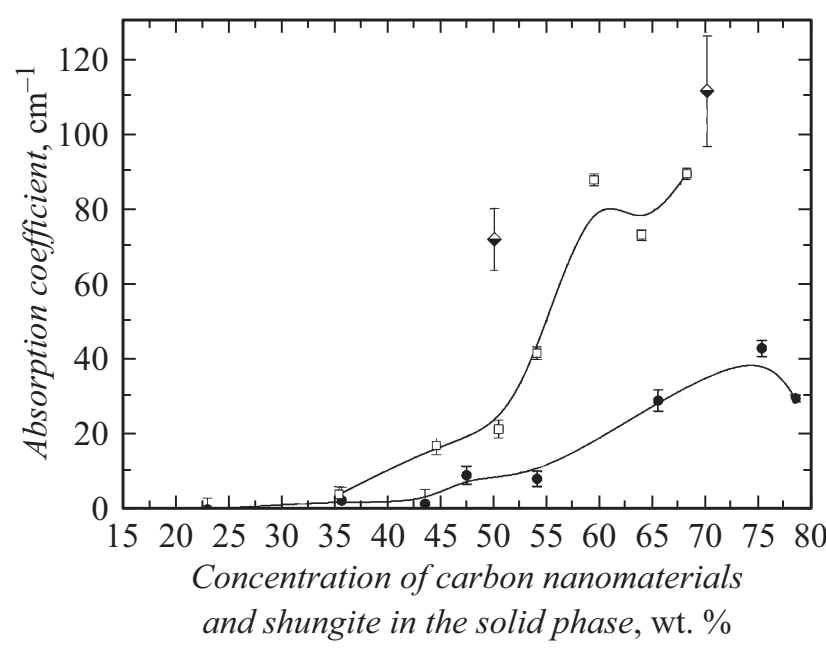

$\rightarrow \quad$ Carbon nanomaterials in butadiene-styrene latex

$\longrightarrow \quad$ Shungite in the butadiene-styrene latex

$\diamond \quad$ Carbon nanomaterials in poly(o-hydroxyamide)

Рис. 2. Поглощение СВЧ излучения композитными пленками на основе УНМ „Таунит-М“ и шунгита в бутадиен-стирольном латексе.

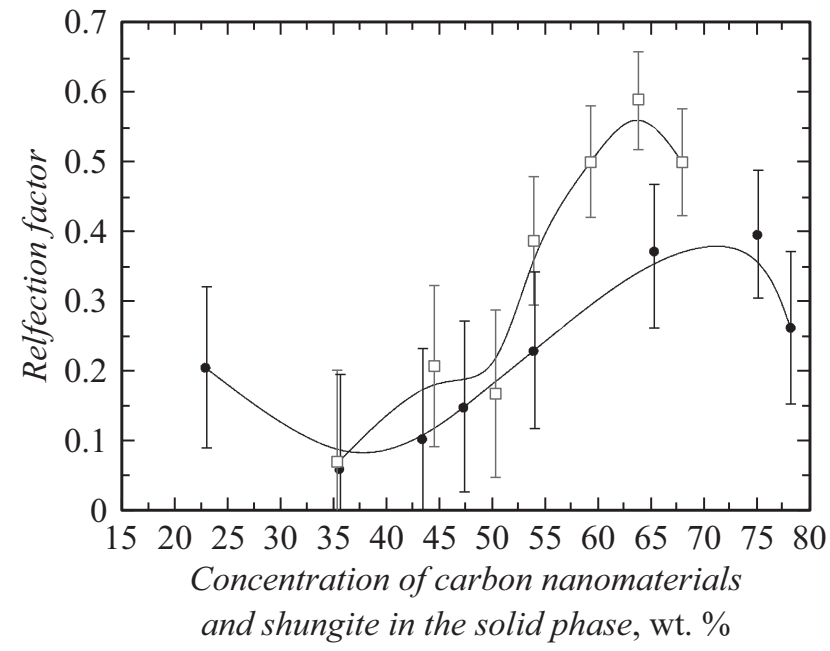

$-\square \quad$ Carbon nanomaterials in butadiene-styrene latex

$\rightarrow \quad$ Shungite in the butadiene-styrene latex

Рис. 3. Отражение СВЧ излучения композитными пленками на основе УНМ „Таунит-М“ и шунгита в бутадиен-стирольном латексе.

Для образцов на основе шунгита примечательно уменьшение показателя поглощения для наивысшей концентрации, что повторяется на концентрационной зависимости электропроводности этих композитов на постоянном токе. Для композитов на основе УНМ нелинейная концентрационная зависимость электропроводности на постоянном токе (рис. 1) принципиально отличается от аналогичной зависимости для шунгита, которая более однородна, а вольт-амперная характеристика близка к 
омической. Поскольку это справедливо также для СВЧ отражения и СВЧ поглощения, можно предположить, что это касается и высокочастотной проводимости.

Полученные данные по СВЧ поглощению лакокрасочных композитных защитных покрытий на основе шунгита и УНМ „Таунит-М“ представляют интерес с точки зрения разнообразных практических приложений.

\section{Заключение}

В ходе проведенной работы созданы жидкофазные композитные лакокрасочные материалы на основе углеродных наноматериалов и органических полимеров (бутадиен-стирольные каучуки, алкидные смолы, поли(о-гидроксиамиды)). Эти композиты позволяют наносить СВЧ защитные покрытия традиционными лакокрасочными методами. Защитные слои, формируемые на основе поли(о-гидроксиамидов) после сушки и прогрева до $350^{\circ} \mathrm{C}$ обладают термо-, хемо-, плазмо- и радиационностойкими свойствами.

Для получения эффективных радиозащитных покрытий необходимо добиваться максимально высокого содержания УНМ в композитах. На основе лакокрасочных материалов с УНМ „Таунит-М““ можно получить защитные покрытия с 80-90\%-ным содержанием углеродных наночастиц.

Работа выполнена в рамках проекта, реализуемого в соответствии с постановлением Правительства РФ от 09.04.2010 № 218 (договор 02.G25.31.0123 от 14.08.2014 г.)

\section{Список литературы}

[1] Makeiff D.A., Huber T., Saville P. // Complex Permittivity of Polyaniline-Carbon Nanotube and Nanofibre Composites in the $X$-band: PMMA Composites. - Defence R\&D Canada-Atlantic, Technical Memorandum, DRDC Atlantic TM 2004-124, 2005. P. 20.

[2] Пат. РФ № 2325417. Способ получения материала для защитного покрытия / Г.П. Алексюк, В.В. Шаманин, Ю.Ф. Бирюлин, Е.И. Теруков, А.Г. Ткачев, В.Л. Негров. 2008. Бюл. № 15.

[3] Пат РФ № 2373246. Способ получения термостойкого материала для защитного покрытия / Л.И. Рудая, В.В. Шаманин, Ю.Ф. Бирюлин, Е.И. Теруков, Н.В. Климова, А.Г. Ткачев, Д.С. Курдыбайло, А.Ю. Марфичев. 2009. Бюл. № 32.

[4] Tselik V., Prikhod'ko A., Raguotis P., Vengalis B. // Tech. Phys. Lett. 1993. Vol. 19. N 12.

[5] Мастеров В.Ф., Приходько А.В., Коньков О.И., Теруков Е.И. // ФТТ. 1997. Т. 39. Вып. 5.

[6] Равич Ю.И., Немов С.А. // Аморфные тела, сплавы и неоднородные среды. СПб.: Изд-во СПбГТУ, 1995. С. 14 18.

[7] Демишев С.В., Косичкин Ю.В., Ларчев В.И., Ляпин А.Г., Попова С.В., Скрочкая Г.Г., Случанко Н.Е. // Письма в ЖЭТФ. 1987. Т. 45. Вып. 12. С. 574-577. 